\title{
Chapter 8 \\ Intensifying Skills Development for New Age Economic Development: Insights from the European Union
}

\author{
Manuela Prina and Georgios Zisimos
}

\begin{abstract}
Abbreviations
Cedefop European Centre for the Development of Vocational Training

ETF European Training Foundation

EU European Union

UNIDO United Nations Industrial Development Organization
\end{abstract}

\subsection{The Role of Skills in European Union Policies}

The world will remember 2020 as the year of the pandemic, the turning point where disruption impacted on all human beings - our way of living, of working, of studying. In Europe, it is also a year we will remember as a turning point, when it was able to deliver the new vision for the European Union (EU) in the midst of a challenging year. In 2020, the EU made a clear choice as regards skills: they are to be the backbone of the EU priorities and vision toward 2030, necessary to realize the so-called "twin transitions"- - one, the vision of a green EU, and two, the ability of all actors and economic sectors to make the best use of digital and technological advancement (European Commission 2020c).

\author{
M. Prina $(\bowtie)$ \\ Directorate, European Training Foundation, Turin, Italy \\ e-mail: Manuela.Prina@etf.europa.eu \\ G. Zisimos \\ Operations Department, European Training Foundation, Turin, Italy \\ e-mail: Georgios.Zisimos@etf.europa.eu
}


In the Treaty of Rome of $1957,{ }^{1}$ the newly born EU made economic and social cohesion one of its pillars to support all member states, in particular by improving the living and working conditions across the Union; and by addressing disparities among member states and across subnational level regions within member states. However, only after almost 20 years after the treaty came into force, or in 1972, did the EU take steps to establish policies. Joint policies focusing on economic, social, and industrial development; and implementation of specific funds-either directed through member state authorities and regional administrators or through direct funding — were put in place to promote skills development needs across all of the EU. Through the European Structural and Investment Funds, ${ }^{2}$ several policies are now being implemented in all member states, particularly in the areas of social inclusion and employment promotion, as well as services targeting employment and improvement of governance for the world of work. Together with the Funds, the EU is investing through specific programs that target areas of joint interest in the member states. Innovation and research ${ }^{3}$ in particular have a key role in ensuring the continuous ability of the EU to anticipate, learn, and adjust its policies and actions for the benefit of society.

Meanwhile, it was only in 2000 - or 48 years after the Treaty of Rome, and 38 years after the start of joint work in the area of social and economic cohesion, industrial development, and regional development_-did the EU make its first joint statement with regard to education and training policies. Before that time, cooperation in the area of education and training was happening at the level of programs targeting higher education, and through the establishment in 1987 of the Erasmus+ program. ${ }^{4}$

\footnotetext{
${ }^{1}$ Tutto sul Parlamento. Treaty of Rome (EEC). https://www.europarl.europa.eu/about-parliament/ it/in-the-past/the-parliament-and-the-treaties/treaty-of-rome.

${ }^{2}$ The European Structural and Investment Funds consist of five funds and represent one of several instruments through which the EU channels funds to its member states. The Funds channel more than half of the EU's resources, and have the objective of supporting job creation toward a sustainable and healthy European economy and environment. The five funds are as follows: (i) European Regional Development Fund aimed at supporting the development of regions within the EU; (ii) European Social Fund, focusing in particular on employment-related projects and human capital development, including education and training for both youth and adults; (iii) Cohesion Fund, focusing on the EU member states where gross national income per inhabitant is less than $90 \%$ of the EU average, and supporting projects in the field of transport and environment in particular; (iv) European Agricultural Fund for Rural Development; and (v) European Maritime and fisheries fund. More information are available at European Commission. Funding programmes and open calls. https://ec.europa.eu/info/research-and-innovation/funding/funding-opportunities/ funding-programmes-and-open-calls_en\#esif.

${ }^{3}$ The budget of the EU for 2021-2027 pays particular attention to the need to invest in research and innovation via Horizon Europe, the European program that supports research and innovation, which in 2021-2027 alone has an allocated budget of 100 billion Euros (source: Horizon Europe European Commission. https://ec.europa.eu/info/horizon-europe_en. Accessed 24 November 2020.) .

${ }^{4}$ Created to support mobility of learners at university level across European Countries, the Erasmus+ (formerly Erasmus Program) is perhaps the most known program of the EU in the area of education and training. Today the program supports mobility not only of learners but also of teaching staff; supports cooperation among learning providers; and supports innovative practices, partnerships, and sector alliances. Erasmus+ is accessible not only to EU member states but to many other countries
} 
The Erasmus+ is the EU's flagship mobility program for students across the EU. Today, Erasmus+ covers almost the entire world and covers not only mobility of students but also mobility of teachers and trainers, and cooperation across education and training providers.

It should be noted that although the Treaty of Rome made no provision for education, it did make a provision for vocational education and training (VET): "The Council shall, acting on a proposal from the Commission and after consulting the Economic and Social Committee lay down general principles for implementing a common vocational training policy capable of contributing to the harmonious development both of the national economies and of the common market" (Article 128, p. 104).

In 2000 in Lisbon, the EU's Head of States asked ministries of education across the Union to start a joint declaration of cooperation to improve education and training across the Union. Hence, in 2003, the European Council adopted the first joint declaration on education and training and established agreed targets to be achieved by 2010 as a first step, then renewing and expanding these by 2020 .

In the Communication on Achieving the European Education Area by 2025 (European Commission 2020b), the EU vision and targets were established for 2030. Regarding VET, the ministers responsible for VET endorsed the Osnabrück Declaration on 30 November 2020, identifying four key priorities for 2021-2025 (Council of the European Union 2020). Apart from the Osnabrück Declaration, there is a plethora of recently enacted EU documents ${ }^{5}$ in the field of education and training, including VET, which stress the role of this domain in economic and societal development, and in supporting the dual green and digital transition.

Skills development is hence part of the EU's policies and cooperation among member states across both economic and education and training dimensions. Both these elements have been present in the history of the EU as important factors shaping societies and citizens across the Union; however, skills development has been following two different tracks of implementation, in particular as regards specific actions addressing different age groups. For youth, the focus is on education and training policies; while for adults, the focus is on skills programs within the European Social and Cohesion Funds' related actions and programs.

With its recent policies through its new vision, the EU has clearly demonstrated the political willingness to ensure support for all citizens in transitioning toward a greener and digitally capable economy and society. The EU has achieved learning as a community and has set new priorities as a result of evidence, consultation, and political vision. It has also translated this learning into specific priorities and actions that embed learning ability and skills development needs across all sectors and dimensions of life of citizens, in both the economic and social milieu.

including Asian ones for specific actions (See European Commission. Erasmus+ https://ec.europa. eu/programmes/erasmus-plus/about_en).

5 These include the European Skills Agenda (European Commission 2020d), Proposal for a Council Recommendation on Vocational Education and Training, Digital Education and Action Plan (European Commission 2020e), and European Education Area. 
From the theory of capacity development, as defined by the European Training Foundation (ETF), we can look at three dimensions or levels that allow for investments in skills to be productive and leading to societal changes (ETF 2014):

(i) the individual level, or the dimension through with most actions have been directed, and favoring individual learning and opportunities for employment;

(ii) the institutional level, where governance of the system is addressed in the ability to create an enabling environment for both skills creation and skills use in a specific sector or theme; and

(iii) the system level, where a clear vision and holistic investments take place, which are conducive to leading the achievement of societal value and public purpose.

\subsection{Skills and the Road Ahead for the European Union}

With the priorities outlined in 2019 by the EU Commission, ${ }^{6}$ there has been a shift on how the EU is looking at skills. For the first time, skills appear as the pillar that underpins all priorities, policies, and actions; and will allow the Union to achieve its vision of becoming the first climate-neutral continent, empowering people through a new generation of technologies, attracting investments, and stimulating the creation of quality jobs, especially for young people and small businesses.

The European Skills Agenda launched in 2020 in the aftermath of the first wave of the coronavirus disease (COVID-19) represents a turning point in the approach of the EU to skills development, particularly as regards the role of skills in supporting the so-called "twin transitions": toward a greener economic era, as well as higher adoption of technology across all spheres of work and life (including access to public services) for all citizens. Although the European Skills Agenda seems to be a continuation of the EU Skills agenda launched in 2016, the new agenda is more coherent and incisive in terms of ambition and targets. It aims to forge alliances with stakeholders, develop tools for lifelong learning, support the provision of skills, and unlock private investments in the provision of skills.

Following several strategic communications, including the one establishing modalities to achieve a common EU education area by 2025, the European Skills Agenda sets out as its vision the integration around skills of first, the central role

\footnotetext{
${ }^{6}$ The priorities set by the European Commission for 2019-2024 are clustered under six chapters: (i) a European Green Deal, composing the core of the vision of the EU to create a green and sustainable society; (ii) a Europe fit for the digital age, ensuring at best the maximization of opportunities posted by digital and technological developments; (iii) an economy that works for people, confirming the focus of the EU pillar of social rights, inclusiveness, and lifelong learning; along with boosting jobs and youth employability programs; (iv) a stronger Europe in the world, with increased attention to development, cooperation, and external relations policies; (v) promoting the European way of life through renewed policies and actions, including a new pact on asylum and migration; and (vi) a new push for European democracy and foresight, with a greater investment in research and innovation (See European Commission. 6 Commission priorities for 2019-24. https://ec.europa.eu/ info/strategy/priorities-2019-2024_en).
} 
of lifelong learning; and second, the need to address skills requirements of all age groups, all sectors of the economy, and all regions of the EU. Apart from its focus on the EU internal market, the agenda also addresses the external dimension of these policies and aspirations, as it recognizes the importance of skills and investments in skills development beyond the EU borders. For the first time, what appears as internationalization of VET is seen as a bidirectional process that combines actions contributing to two drivers: the globalization of markets and labor force, and the intrinsic need of education and training systems to learn from each other and expand their circle of cooperation.

In a nutshell, the EU has made future transitions and a clear societal model (greener, inclusive, and fair) the basis for all of its policies and priorities for the next decade. This need has been backed up by additional funding, in particular for research and innovation, youth, skills development for all economic sectors, and a strong digital agenda.

The international dimension of these EU education and training developments is clearly outlined in many policy documents that recognize not only the need for cooperation among EU member states, but across the world. Vocational education and training, in particular, is being asked to contribute to response strategies for unprecedented incidents (see European Centre for the Development of Vocational Training [Cedefop] 2020, p. 3).

The trajectory of the EU policies and actions is based on a concept of continuous learning and policy adjustments, grounded on a strong evidence and monitoring culture, innovation and research investments, and a solid social and participatory dialogue that allows capture of and building on diversity to anticipate the multiple demands of society.

The merits of the European Skills Agenda, among the many priorities and actions outlined, are (i) the strong recognition of the role of skills in supporting the economic and social aspirations of the Union; (ii) the focus on all stages of life, modalities of skills development, and recognition of skills; and (iii) the strong responsibility reposed in all levels of governance, from international policy dialogue and steering, to sector dialogue and cooperation at the European, national, and local levels.

COVID-19 has strongly impacted the European Union, specifically at a time new priorities were being launched and new policies developed. The impact of COVID-19 on the economy has pushed the EU to further prioritize its focus on skills development as an essential investment for the future. In order to give a concrete response to emerging demands created by COVID-19, and because of the necessity to support citizens in the transition toward a greener and more digital society, the EU has added to the 2021-2027 long-term budget a temporary recovery instrument called nextgenerationEU. This recovery fund will not only support the necessary social measures during this time of crisis but will mainly be allocated to modernization through research and innovation, digital development and support, and skills development across all programs. 


\subsection{Instruments for Skills Development Toward a New Economic Age}

There are both consolidated as well as new features that the EU has adopted to support the transition to a green and sustainable economy by 2030 . In terms of continuation of consolidated successes, on one hand, we see the confirmation of the "policies, strategies-actions-funding scheme" implemented in the previous decades, providing specific access, i.e., funds and competent support, to funding opportunities, research and innovation, as well as targeted skills development support at the level of regions, sectors, and specific target groups of citizens across the Union. Several funds, including the European Pillar of Social Rights ${ }^{7}$ reconfirm priorities of actions to support joint targets such as the reduction of youth unemployment and the support to transition measures. Several instruments in place since the 2000s have been reconfirmed, such as the European level policies and practices focused working groups, thereby allowing for technical steering and policy learning across member states. Other programs that constitute the backbone of cooperation in education and training among member states as well as countries outside the Union are also given renewed support.

Other actions, such as those targeting the New Industrial Strategy for Europe ${ }^{8}$ and the European Digital Strategy, ${ }^{9}$ allow for observation of the shift under the current EU Commission and leadership toward a more closely integrated vision of economic development and clear purpose led by the Union, marked by greening, sustainable competitiveness, social fairness, and resilience. These targets are to be reached through a more holistic and integrated attention to all levels of capabilities - from the individual to skills development for all, and to the institutional and organizational-including supporting new governance modes and modalities of work, services and access to them, and private sector efforts at transformation and transition. At the system level, this will be pursued through a stronger alignment across the Union.

Other new features include the stronger focus on cooperation, through what the European Skills Agenda calls "pact for skills" to be implemented at the sector level. Also included are several levels of governance from international to local; and more actors to develop virtuous cooperation and ecosystems for skills development, job creation, and economic transformation. Also important in the new approach is the revisited targeted of adult participation in training opportunities. This target has been maintained at $10-15 \%$ until 2020 . It is now set to cover $50 \%$ of the adult population

\footnotetext{
${ }^{7}$ The European Pillar of Social rights outlines three priority areas for the EU: (i) equal opportunities and access to the labor market, (ii) fair working conditions, and (iii) social protection and inclusion. The full text can be found at European Commission. European pillar of social rights. See https://ec.europa.eu/info/strategy/priorities-2019-2024/economy-works-people/deeper-and-fai rer-economic-and-monetary-union/european-pillar-social-rights_en.

${ }^{8}$ See European Commission (2020c) for the New Industrial Strategy for Europe.

${ }^{9}$ The European Digital Strategy is accessible at https://ec.europa.eu/digital-single-market/en/con tent/european-digital-strategy.
} 
in Europe by 2025. The need for retraining, upskilling, and reskilling is meant to derive from the strong focus on transition toward a greener and more digital EU, and also in response to the impact of COVID-19 on societies, business models, and needs to confront the crisis and future recovery.

Finally, the European Skills Agenda has a greater focus on the external dimension of the EU policies; on dialogue with countries outside the EU; and cooperation in the areas of skills development, innovation, and social and economic cohesion. There is more openness across the programs and funding opportunities to countries outside the EU, as well as cooperation among EU actors and third countries. Support to mobility as well as measures to address migration are established, particularly through the new pact of asylum and migration ${ }^{10}$ where both legal migration and labor mobility, as well as addressing the root causes of illegal migration, sees skills as one of the key assets for success of these policies and measures.

\subsection{Impact of Coronavirus Disease: Crash Test and Reality Check}

The COVID-19 outbreak hit the EU just as the newly established European Commission was ready to launch its policies and actions for its mandate. Throughout the emergency, the EU has confirmed its priorities and vision, making the impact of COVID-19 an accelerator to push forward several actions with an even stronger public purpose and sense of urgency as regards the need to immediately turn policies into action.

The EU has organized its COVID-19 response across several channels, in response to the immediate challenges posed by the health emergency and subsequent crisis. Much effort has been exerted to address employment and social cohesion, including support to young people, economic support to small businesses, and incentives for innovation and research. Moreover, for the longer term, the lessons learned from these times of disruption will be integrated into new societal and economic models.

Studies conducted by the (ETF 2020) and the United Nations Industrial Development Organization (UNIDO) ${ }^{11}$ on the impact of COVID-19, particularly on socioeconomic needs and skills, outline that most public measures put in place for crisis management and recovery have failed to look at skills as an asset for support. Despite the recognition by economic actors, in particular industries and small and medium-sized businesses, on the urgent need for reskilling and upskilling, most companies were not informed about opportunities being offered by public players. The European Company Survey released in the fall of 2020 (Eurofound and Cedefop

\footnotetext{
${ }^{10}$ See European Commission (2020a) for The New Pact on Asylum and Migration.

${ }^{11}$ UNIDO Learning and Knowledge Development Facility. Global survey analysis: changing needs for skills development as a result of COVID-19. https://lkdfacility.org/resources/global-survey-ana lysis-changing-needs-for-skills-development-as-a-result-of-covid-19.
} 
2020) reveals that companies in the EU offer training but fail to have a future-looking and holistic approach to skills development.

The outbreak of COVID-19 and its impact on all aspects of the socioeconomic life of individuals and organizations have accelerated the understanding of how several disruptions and potential transformations can be taken on board, and what gaps are there to move from vision, to implementation, to realization.

COVID-19 has further accelerated the need to support the EU's future transitions, and to support and guarantee cohesion and inclusion across all member countries in a time of crisis and recovery, in pursuit of the EU's new "greener, inclusive, and fair" societal model. COVID-19 is a reality check, a solid baseline to assess the ambitious EU agenda and vision for the future, and to gauge current capabilities at all levels of governance and all actors involved in realizing the EU vision.

At the level of education and training, the impact of COVID-19 has affirmed most of the priorities already addressed at the policy level, such as the need to focus on key competencies; the importance of investing on teachers and trainers; the growing inequalities with respect to the use of technologies, access to technology, and connectivity; and the crisis of learning across all countries of the world.

The gap between the highly purposeful and inspiring vision and policies put in place at the EU level met a strong crash test when confronted with the realities on the ground. There is a wide gap to be filled, both in the world of work and the world of education and training, to ensure that Europe can confidently move toward its targets by 2025 and the realization of its vision by 2030 .

\subsection{From International Policies to Local Implementation: The Case of Turin}

One of the most important dimensions in skills development is the level of local governance. Regions, cities, municipalities are the epicenter of the cooperation and action that translate policies into facts.

Between 2019 and 2020, the ETF together with the International Training Centre of the International Labour Organization (ITCILO) joined forces with the City of Turin, which was hosting both institutions on the occasion of ETF's 25 years of operation, and ITCILO's 100 years. Turin was guiding a dialogue at the city level on the role of skills in supporting the vision of the city to become an innovation hub. The initiative, named Torino Skills City, ${ }^{12}$ examined within a period of 6 months the following: (i) actors needed around the table to address skills demands to realize the economic vision of the city, (ii) identification of challenges facing the city in realizing its potential, and (iii) solutions built on global exchange with experts from the international arena.

\footnotetext{
12 More information on the project is accessible at European Training Foundation. Torino Skills City: solutions to global challenges in the city. https://www.etf.europa.eu/en/news-and-events/news/ torino-skills-city-solutions-global-challenges-city.
} 
Being historically an industrial city, Turin was home to one of the most important districts in the automotive sector. Still retaining some of its industrial history, the city is now home to one of the innovation hubs of Italy, and has invested in the aerospace industrial cluster while having a strong presence in the agriculture and agri-food sectors. As part of its vision for the future, the Turin administration has reserved a prominent role for innovation testing and prototyping to attract investments, start-ups, and international companies to the city. This vision is shared by stakeholders working with the city administration under the Torino City Lab, ${ }^{13}$ an initiative led by the deputy mayor for innovation.

Two leading universities in Turin, namely the Università degli Studi di Torino and the Politecnico di Torino, play a major role in the transformation of the city. They have absorbed much of the industrial know-how and developed research and innovation structures to become world-class knowledge hubs. As there had been limited reflection on skills development-which was the focus of the dialogue between Torino City Lab, ETF, and ITCILO_critical challenges have been identified by stakeholders upon analyzing the role of skills in achieving the vision for the future of Turin and the aspirations of Torino City Lab. These challenges reflect the gap that could be found at the local level, which needs to be addressed to ensure that the vision for a new economic era can be realized:

(i) Digital skills development. Stakeholders pointed to the need to invest on digital skills not only at the level of education and training of young people, but also of public administration and citizens, so as to correctly access and use digital services that will be developed in the future.

(ii) Cooperation among actors. One of the elements outlined as critical by stakeholders is the need to move away from working groups that are either sector- or age-specific, to working groups and policies that are transversal; which address a domain; and which allow for synergies, partnerships, and joint projects that bring together diverse competencies.

(iii) Steering a culture of innovation. Across both public and private sectors, the resistance to innovation and change has been identified as an area of concern needing resources and specific competencies. To increase the openness to innovation, funding and services that can support both education and training, as well as enterprises, to embrace opportunities for the future are needed.

(iv) Foresight. A clear focus on "what is coming next" based on solid evidence and data was identified as a critical factor for success in setting up a clear strategy to achieve a shared vision. Likewise, a permanent observatory that allows for policy steering and collects inputs from all actors involved in the ecosystem is needed.

\footnotetext{
13 Torino City Lab is a project of the City of Turin aimed at supporting the development of a virtuous ecosystem, enabling the attraction, creation, and impact of innovation for the city. Several actions take place under the umbrella of Torino City Lab, including cooperation in the area of education and training, research and innovation investments, and innovation for social impact. See Torino City Lab. https://www.torinocitylab.it/it/.
} 
(v) Transitions guidance. An important feature identified by city stakeholders stemmed from the discussion on inclusion and career guidance for young people. Continuous guidance from the city, learning from consolidated services provided to young people and to the unemployed, and expansion of the concept to serve other target users will support each citizen in the transition toward a new way of living and working. These abilities were deemed critical for the city to support the population through several transitions in their career and work environment.

(vi) Attracting and retaining talent. A shared need expressed by both private and public actors focused on attraction of talent. New competencies are needed at all levels in private companies and in public administration, and also among training and education providers. Likewise, there is need to focus on possible new forms of work, including those offered by distance cooperation and digital and smart working. This dimension poses new challenges and requires new legislative frameworks and international rules, to avoid an even more aggressive competition for talent across the EU and the world.

These lessons learned from the specific observation of a case study highlight the concrete challenges that can ensure successful implementation of policies given the diversity of needs, local realities, and sectoral developments.

The impact of COVID-19 has further widened the gap between policy setting and implementation, and raises an alarm as regards the need to take into account diverse needs and realities. Inclusion must be ensured as a part of both policy formulation and implementation, to allow strong ownership among local level stakeholders. A diffuse leadership approach is called for, where different organizations can take the lead in coordinating and steering specific chapters of a shared vision.

\subsection{Skills and Challenges Ahead to Realize a New Economic Age}

The EU vision, policies, and instruments put in place are a model not only for Europe but for the world as it tries to achieve at the global level the Sustainable Development Goals by 2030, where sustainability, social fairness, and resilience are key features shared by all countries that have adhered to the 2030 agenda.

First, as skills development has finally become a transversal pillar for the EU across all policy dimensions, the 2030 agenda cannot be achieved if the question "what skills are needed to achieve this specific goal" are not addressed and transformed into action. Cities will not be better if skills are not there to make them better; the seas and the environment will not be managed in a sustainable way; and cooperation among actors will not take place. It is through skills that we can achieve the change we want. Therefore, it is fundamental to ensure that skills development is not confined to a single dimension; rather, it should be the question that underpins all levels of change: individuals, organizations, societies. 
Second, it is key to ensure a continuum across the vision statement, policies and strategies, funds, and actions. Missing out on any of these elements will have a negative impact on all.

Third, skills development cannot be seen solely as a role for the education and training systems. Skills development policies need to be perceived as an ecosystem: from problem statement, to solutions, to tools, and to actors involved. This is why the role of local governments, city, and regional stakeholders; and sector dialogue and skills pacts at the sector and local level, are key assets for success when looking at achieving a vision and accompanying any transition.

Fourth, we need to ensure that new demands in skills development and use of skills are considered, so that we can maintain a certain flexibility in policies to be able to cater to change. Some of these changes are the new forms of work, where the possibility of increasing the number of digital workers, and the possibility of economies integrating and hiring workforce "from a distance", will affect social fairness, labor legislations and rights, and skills development and usage across the world.

Fifth, we need to ensure that skills form part of each measure we design and put in place. Be it for the public or private sector; be it for education and training of youth, adults, or elderly, skills are key to achieve transformation, ensure social fairness and inclusion, and put in place the conditions to create the world of tomorrow, as well as use the opportunities that will arise.

Finally, the case of the City of Turin in Italy brings us to the importance of focusing on implementation and outlines several crash tests to be done when moving from a policy statement to realization of concrete change for all citizens. The need to ensure a holistic and cooperative approach to policy domains and actions must be complemented by a strong focus on innovation, communication, and diversity of engagement strategies so that all actors and all citizens could successfully become part of the desired change.

\subsection{Conclusions}

Facing change in societies is not a new story for human beings. The pace of change makes disruptions more frequent and thus demands quicker adaptations. The impact of innovation linked to technological advancement; the embedding of the digital world in all spheres of life and work; and the disruptions in how societies organize themselves, perceive problems, and face new and demanding challenges such as climate change or rising inequalities, bring new complexities to the table. Learning as a society and developing skills as individuals and organizations within a society, comprise part of the solution when we look at disruptions from both an individual as well as societal point of view. For society, it is key to have in place a learning cycle that allows to anticipate and mitigate risks, and maximize benefits from disruptions to transform them into opportunities. For an individual, it is key to learn throughout life, 
to acquire skills, to develop and enhance own competencies, and to meet changing demands while cultivating one's own talent.

As we argue in this chapter, a learning society is not only about having isolated educated and skilled citizens. It takes multiple and complex interactions to grow an ecosystem that connects, supports, and makes the best out of individuals' learning. Formal learning institutions like schools and universities, enterprises, local and regional authorities, research institutions. and local communities need to contribute to create and support ecosystems of skills and competencies. Within the EU context, such ecosystems are the root source of innovation and development and can strengthen sustainable competitiveness while ensuring social fairness.

Will the world achieve its inspiring 2030 agenda and be able to recover from the impact of COVID-19?

This is a complex question that cannot be answered with a simple yes or no. Even if we take for granted that sooner or later, COVID-19 will be defeated, the question of recovery and catching up with the burning issues that societies had even before the pandemic still needs to be addressed.

The paper argues that in this process of recovery and reignition, the ability of countries, regions, or cities to respond will depend on the skills capacity of their citizens. Transition toward a greener and more sustainable societal model requires that societies adopt a learning model embracing all citizens of all ages, working status, and social conditions.

To respond to such a diverse and intensified provision of skills where upskilling and reskilling are equally important as skilling, a new approach is needed that blends together age, geographical, societal, and individual needs. This new age of economic development will reveal the value of networking for the development of more dynamic partnerships even between stakeholders who had traditionally worked in isolation. Striving for excellence as a process of continuous improvement will become the new norm for such partnerships to happen.

The EU through its history and its priorities for the future sets a model as regards learning societies. There are two ways the EU shall be considered as a lighthouse when looking at learning societies. First, since its early days, the EU has placed learning at the heart of its vision and policies, identifying needs and areas for cooperation among member states, and between the EU and external actors. The second is the vision of the EU for the future, reinforcing the investment on skills on the basis of anticipated needs and vision, and learning from its stakeholders to address needs that are at the basis to realize the transition toward a greener, fair, and resilient society. This vision is backed by an unprecedented investment in skills and innovation areas for EU member states, where the financial envelope for 2021-2027 has been increased through an additional investment called the "NextGenerationEU" (European Union 2020).

Funds for flagship programs of the EU focused on skills and excellence, mobility of learners and teachers, and cooperation in the area of education and training have doubled as compared to the amounts of the previous programming cycle of the EU. Despite uncertainties and proving the commitment of the EU to a global sustainable agenda, the budget for external actions and humanitarian aid has increased in the new 
financial perspective. This follows the "New Consensus on Development" where the EU declares,

Ensuring access to quality education for all is a prerequisite for youth employability and longlasting development. The EU and its Member States will support inclusive lifelong learning and equitable quality education, particularly during early childhood and primary years. They will also promote education at secondary and tertiary level, technical and vocational training, and work-based and adult learning, including in emergency and crisis situations. Special attention will be paid to education and training opportunities for girls and women. The EU and its Member States will intensify their efforts to ensure everyone has the knowledge, skills, capabilities and rights they need to enjoy a life in dignity, to be fully engaged in society as responsible and productive adults, and to contribute to the social, economic and environmental well-being of their communities. (Article 28 in European Commission 2017, p. 11)

The EU is an engine that has a declared interest to support skills development as a driver for change and growth, increasing its future budget allocations for external assistance and for youth and skills programs across all its priorities. The importance to society of learning, both in the ability to anticipate and manage change, as well as to ensure a continuous and accelerated learning process throughout systems, organizations, and individuals, is even greater than ever.

External partners of the EU, in Asia in particular, will be called upon for a reinforced cooperation with the EU in the field of skills development; adaptation of skills; and shared vision as regards greening, social fairness, and innovation. This will include renewed cooperation in the formal education domains, for example through the Asia Europe Meeting bringing together 51 countries from Europe and Asia to discuss cooperation in the area of education and training. It will also include renewed attention to labor rights and social demands in trade agreements, and renewed attention to upskilling and reskilling across economic sectors to contribute to a wider transition toward the realization of the 2030 Agenda, which the EU supports in full through its policies and investments in the world.

The decade ahead will test several EU policies, responses, funding instruments, and programs aimed at bringing transition and positive results for the 2030 agenda. The vision and political commitment are clearly there, and now is the time for implementation.

\section{References}

Council of the European Union. 2020. Osnabrück declaration on vocational education and training as an enabler of recovery and just transitions to digital and green economies.

Eurofound and European Centre for the Development of Vocational Training (Cedefop). 2020. European company survey 2019: Workplace practices unlocking employee potential. European Company Survey 2019 Series. Luxembourg: Publications Office of the European Union. https:// www.eurofound.europa.eu/sites/default/files/ef_publication/field_ef_document/ef20001en.pdf.

Cedefop. 2020. Osnabrück Declaration on vocational education and training as an enabler of recovery and just transitions to digital and green economies. https://osnabrueck_declaration_e u2020.pdf (europa.eu). Accessed 8 January 2021. 
European Commission. 2021-2027. Long-term EU budget and next generation EU. https://ec. europa.eu/info/strategy/eu-budget/long-term-eu-budget/eu-budget-2021-2027_en. Accessed 8 January 2021.

European Commission. 6 Commission priorities for 2019-24. https://ec.europa.eu/info/strategy/pri orities-2019-2024_en. Accessed 24 November 2020.

European Commission. Erasmus+. https://ec.europa.eu/programmes/erasmus-plus/about_en. Accessed 24 November 2020.

European Commission. European pillar of social rights. https://ec.europa.eu/info/strategy/priori ties-2019-2024/economy-works-people/deeper-and-fairer-economic-and-monetary-union/eur opean-pillar-social-rights_en. Accessed 24 November 2020.

European Commission. Funding programmes and open calls. https://ec.europa.eu/info/researchand-innovation/funding/funding-opportunities/funding-programmes-and-open-calls_en\#esif. Accessed 24 November 2020.

European Commission. The European digital strategy. https://ec.europa.eu/digital-single-market/ en/content/european-digital-strategy. Accessed 24 November 2020.

European Commission. 2020a. A fresh start on migration: Building confidence and striking a new balance between responsibility and solidarity. Press release. September 23. https://ec.europa.eu/ commission/presscorner/detail/en/ip_20_1706. Accessed 24 November 2020.

European Commission. 2020b. Communication from the Commission to the European Parliament, the European Council, the European Economic and Social Committee and the Committee of the Regions: Achieving the European education area by 2025. Achieving the European Education Area by 2025-Communication I Education and Training (europa.eu). Accessed 11 January 2021.

European Commission. 2020c. Communication from the Commission to the European Parliament, the European Council, the European Economic and Social Committee and the Committee of the Regions: A new industrial strategy for Europe. https://ec.europa.eu/info/sites/info/files/commun ication-eu-industrial-strategy-march-2020_en.pdf.

European Commission. 2020d. European skills agenda for sustainable competitiveness, social fairness and resilience. https://ec.europa.eu/social/main.jsp?catId=1223\&langId=en. Accessed 8 January 2021.

European Commission. 2020e. Proposal for a council recommendation on vocational education and training (VET) for sustainable competitiveness, social fairness and resilience.

European Commission. 2017. The new European consensus on development. https://european-con sensus-on-development-final-20170626_en.pdf. (https://europa.eu).

European Training Foundation (ETF). Torino skills city: Solutions to global challenges in the city. https://www.etf.europa.eu/en/news-and-events/news/torino-skills-city-solutions-global-cha llenges-city. Accessed 8 January 2021.

ETF. 2014. Capacity for the development of human capital: The role of vocational education and training. https://www.etf.europa.eu/en/publications-and-resources/publications/capacity-dev elopment-human-capital-role-vocational. Accessed 8 January 2021.

ETF. 2020. Coping with COVID-19 mapping COVID-19-The socio-economic impact: The future of skills in the EU neighbourhood. https://www.etf.europa.eu/sites/default/files/2020-07/map ping_covid_030720_socio_economic.pdf.

European Union. 2020. EU'S next long-term budget \& NextGenerationEU: Key facts and figures. https://mff_factsheet_agreement_en_web_20.11.pdf (europa.eu).

Horizon Europe European Commission. https://ec.europa.eu/info/horizon-europe_en. Accessed 24 November 2020.

Torino City Lab. https://www.torinocitylab.it/it/. Accessed 8 January 2021.

Treaty of Rome. https://eur-lex.europa.eu/eli/treaty/teec/sign. Accessed 8 January 2021.

Tutto sul Parlamento. Treaty of Rome (EEC). https://www.europarl.europa.eu/about-parliament/it/ in-the-past/the-parliament-and-the-treaties/treaty-of-rome. Accessed 8 January 2021.

United Nations Industrial Development Organization (UNIDO). Learning and Knowledge Development Facility. Global survey analysis: changing needs for skills development as 
a result of COVID-19. https://lkdfacility.org/resources/global-survey-analysis-changing-needsfor-skills-development-as-a-result-of-covid-19. Accessed 8 January 2021.

UNIDO and ETF. 2020. Changing needs for skills for skills development as a result of COVID-19. https://lkdfacility.org/wp-content/uploads/Changing-needs-for-skills-development_ UNIDO_ETF_2020.pdf.

The opinions expressed in this chapter are those of the author(s) and do not necessarily reflect the views of the Asian Development Bank, its Board of Directors, or the countries they represent.

Open Access This chapter is licensed under the terms of the Creative Commons Attribution-NonCommercial 3.0 IGO license (http://creativecommons.org/licenses/by-nc/3.0/igo/) which permits any noncommercial use, sharing, adaptation, distribution and reproduction in any medium or format, as long as you give appropriate credit to the Asian Development Bank, provide a link to the Creative Commons license and indicate if changes were made.

Any dispute related to the use of the works of the Asian Development Bank that cannot be settled amicably shall be submitted to arbitration pursuant to the UNCITRAL rules. The use of the Asian Development Bank's name for any purpose other than for attribution, and the use of the Asian Development Bank's logo, shall be subject to a separate written license agreement between the Asian Development Bank and the user and is not authorized as part of this CC-IGO license. Note that the link provided above includes additional terms and conditions of the license.

The images or other third party material in this chapter are included in the chapter's Creative Commons license, unless indicated otherwise in a credit line to the material. If material is not included in the chapter's Creative Commons license and your intended use is not permitted by statutory regulation or exceeds the permitted use, you will need to obtain permission directly from the copyright holder.

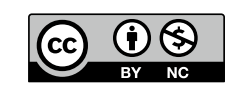

